\title{
Representações da velhice e do envelhecimento na obra de Dias de Melo
}

\author{
Maria João Dodman ${ }^{1}$
}

\begin{abstract}
Todos começamos a morrer no mesmíssimo momento em que começamos a viver. A partir daí cada instante, cada dia que vivemos é, em nós, um dia de recuo da vida e avanço da morte - ou, por outras palavras, um dia perdido pela vida, um dia ganho pela morte.
\end{abstract}

Dias de Melo, Milhas contadas

O envelhecimento e a velhice têm sido, até recentemente, categorias invisíveis, praticamente desconhecidas tanto ao nível da crítica literária, como em todas as demais disciplinas das Humanidades. Os motivos podem resumirse em poucas palavras: a velhice tende a ser vista apenas como etapa final, fase de declínio, propícia à doença, ao enfraquecimento e à inevitável morte. Ao falarem dos estudos sobre a velhice, Sara Deats e Lagretta Lenker (1999, p. 1-3) assinalam o predomínio de um discurso homogéneo fixado principalmente num processo biológico de deterioração física e cognitiva e, portanto, dificilmente se conseguem construir novas e positivas visões sobre o assunto. Embora o envelhecimento seja um processo comum a todos os organismos vivos, há no ser humano implicações psicológicas e sociais relacionadas com o que Beauvoir (p. 1972, p. 1-3) intitula uma conspiração de silêncio destinada a esconder a criminalidade social relativa à marginalização do idoso. Por sua vez, Paul J. Archambault (1989, p. 55) identifica as grandes contradições do mundo moderno quanto ao tratamento do idoso. Por um lado observa-se que atualmente existem, mais do que nunca, sociedades envelhecidas, resultado de melhores condições de vida e de avanços médicos. Por outro lado, como explica Archambault (1989, p. 54-55), os idosos são vítimas não só de exploração, mas também de apatia e de completo desinteresse, tanto literário como sociológico. Segundo o referido crítico, este fenómeno já era notável no século XIX com a chegada de uma classe comercial urbana e a subsequente exploração capitalista. Nota-se uma

${ }_{1}$ Doutora em filosofia e professora do Departamento de Línguas, Literaturas e Linguísticas da York University, Toronto, Canadá. E-mail: mdodman@yorku.ca 
mudança em relação à situação e à imagem dos idosos, especialmente os mais pobres: antes eram seres humanos que mereciam e recebiam veneração, tendo autoridade e utilidade social, e depois passaram a ser explorados e considerados prescindíveis (1989, p. 54). Em Aging and its discontents, Kathleen Woodward (1991, p. 7-8) afirma que a velhice produz ansiedade, medo, rejeição e repressão e que a nossa cultura tem uma postura profundamente ambivalente, mas sobretudo negativa, com respeito à velhice. A partir de uma análise psicanalítica, Woodward alega a cumplicidade de, entre outros, Freud, na construção de uma visão da velhice como deformação, assinalando que "não encontramos nem em Freud nem em outros discursos dominantes, a velhice representada, por exemplo, em termos de novas formas criativas da idade avançada" (WoodWARd, 1991, p. 10). Pat Thane (2005, p. 268) confirma ainda a percepção negativa quanto aos idosos, percepção esta que os leva a tornaremse ou dependentes dos jovens, ou a serem vistos em relação ao que já não são, ou seja, cidadãos ou trabalhadores produtivos, como o eram outrora. Um dos problemas mais graves é a nossa incapacidade em compreendermos que a velhice é, de facto, um processo heterogéneo (DeAts; Lenker, 1999, p. 4; DeFAlco, 2010, p. 2) que inclui diversidade, harmonia de contrários, sabedoria, características identificadas por gerontologistas modernos, e que diferem daquelas usualmente associadas aos estereótipos tradicionais sobre a velhice (DeATs; LenKer, 1999, p. 7).

Em termos de produção literária e artística, vários são os críticos que assinalam a exclusão do idoso destas áreas. Richard Fallis (1989, p. 35-36), por exemplo, nota que as personagens idosas são de facto marginalizadas, periféricas à ação, limitadas na sua maioria às imagens de decadência física, uma inevitabilidade que a juventude prefere ignorar. As representações da velhice consideradas socialmente aceitáveis dão relevo ao idoso como figura sábia e venerável. Um exemplo desta tradição na literatura portuguesa é a bem conhecida figura camoniana do Velho do Restelo, cujo discurso nos acautela sobre os males da ambição e os perigos inerentes a condutas impróprias e imorais. Simone de Beauvoir também nos diz que o idoso tende a ser visto como um ser puro, sábio, rico em experiência e sempre virtuoso. Ter defeitos ou exibir os mesmos desejos ou ambições que um jovem, são, para o idoso, facetas inaceitáveis. Nos dois casos, como explica Beauvoir (1972, p. 3-4), o idoso é considerado um ser diferente, que existe apenas 
numa vertente virtuosa ou degradante, mas sempre marginal ao resto da humanidade.

Bem patente é a nossa falta de compreensão face aos idosos menos sábios ou nada veneráveis. O dramaturgo português Gil Vicente, para além do agudo e severo criticismo que faz à nobreza e ao clero, revela-se igualmente crítico em relação aos idosos. José I. Suárez menciona vários exemplos encontrados na obra deste autor. Entre outros, o velho da horta, da obra do mesmo nome, e o juiz de Floresta de enganos, que se apaixonam por mulheres jovens e se comportam de maneira decididamente nada virtuosa. Por este motivo, são personagens severamente castigadas e vítimas de partidas cómicas e até cruéis. Segundo Suárez (1997, p. 41-42), o que é risível não é a velhice, mas sim o facto de que os velhos, nestas e noutras obras, não aceitam a sua velhice e mostram atitudes e desejos contrários aos considerados aceitáveis.

O escritor açoriano José Dias de Melo dispensa apresentação. Bem conhecida é a sua obra, especialmente na região dos Açores, por ser esta a fonte de inspiração e o palco da maior parte das suas obras. Sendo uma das grandes vozes literárias açorianas, Dias de Melo é popularmente reconhecido como o escritor da caça à baleia devido à sua clássica trilogia Mar rubro, Mar pela proa e Pedras negras. É facto indiscutível que foi Dias de Melo quem imortalizou a saga baleeira, a vida sofrida da gente humilde e o seu povo. No entanto, a obra de Dias de Melo não pode, nem deve, ser lida apenas dentro dos horizontes limitados da ilha, mas sim na sua universalidade. Dias de Melo abre a ilha ao mundo e o mundo à ilha, ou seja, embora ancorado na realidade insular, o escritor discute e estabelece um diálogo universal, nutrido pelo compromisso à justiça e à dignidade daqueles que carecem de voz. Figuram precisamente entre os mais carenciados, os idosos. Ao contrário das obras literárias atuais que, sistematicamente, excluem os idosos, estes aparecem com frequência na obra do escritor açoriano. De facto, o envelhecimento, muitas vezes prematuro, não lhe passa despercebido e o seu tratamento e representação não são por ele evitados nem ignorados.

Embora talvez mais acentuadas nas últimas décadas, devido à idade já avançada do escritor, a ternura e a admiração pelos idosos estão presentes já nas primeiras obras. Basta recordar alguns dos casos mais representativos. Em 
"Serão Açoriano", da coletânea de poemas Toadas do mar e da terra (1954, p. 89), declama a voz poética:

\author{
Vai o serão p'la noite dentro. \\ Sentam-se, na larga esteira, \\ velhos, novos e crianças \\ junto ao fogo da lareira. \\ Os velhos sabem tanta coisa!... \\ E as crianças, encantadas, \\ ouvem histórias de baleias, \\ de princesas e de fadas.
}

Se bem que este exemplo possa ser interpretado de acordo com a visão clássica do idoso como figura sábia e venerável, aparece aqui outra faceta importante: o papel do idoso na memória, agente de retenção e transmissão do património cultural ilhéu, hoje em vias de extinção. Estas histórias de baleias, fadas, princesas e outros contos servem também de elo intergeracional, representativo da relação de respeito mútuo, do diálogo e da convivialidade entre jovens e idosos. Vejamos, por exemplo, o caso dos avós em Pedras negras:

Os dois velhos embalavam o bercinho dos netos. [...] Ouviam-lhes, com seus ouvidos rijos, o balbuciar dos primeiros murmúrios. Amparavam- lhes, com a força da sua fraqueza, a tentativa dos primeiros passos. As primeiras histórias de fadas e princesas que embeveceram seus corações de crianças - foram eles, os avós, que lhas contaram. E para os adormentar, mesmo já crescidinhos, o velho tocava na sua viola e a companheira cantava (MELo, 2008, p 138).

Dos idosos aprendem-se lições de vida, recorda-se o passado e preserva-se a memória do povo. De facto, ao ler algumas das obras de Dias de Melo, ficamos com a sensação de um retorno a um passado mais simples, e talvez mais digno, pela valorização que se dá ao idoso. Por exemplo, em "Carta com destino" - do livro de contos À boquinha da noite -, o escritor partilha connosco uma comovente carta de uma leitora anónima sobre o livro Reviver: na festa da vida a festa da morte:

Fiquei maravilhada com o livro de ponta a ponta, senti-me cativada por cada palavra, cada linha que li ao longo das 314 páginas que dura a história. Muitas delas trouxeram-me à memória pessoas que há algum tempo não vejo, porque já não fazem parte do nosso mundo. Senti saudades do meu avô e da minha avó, porque a vida deles terá sido assim e, enquanto lia o livro, por vezes os olhos ficaram marejados de lágrimas e eu senti o cheiro da luz de petróleo em casa da minha avó, lembrei-me de quando ela fazia bolo de milho, da vaquinha "Estrela" que meu avô tinha na atafona atrás de casa, de quando fomos para a vinha vindimar. Estou como quem os está vendo. Minha avó baixinha, rechonchuda, 
com os óculos, meu avô magrinho, de chapéu de palha, sempre ligeirinho. Quis Deus levá-los repentinamente e deixar esta saudade (Melo, 2001b, p. 9-10).

Assim, em muitas obras de Dias de Melo, os idosos não são marginalizados nem vivem para além da humanidade, como diria Beauvoir, mas sim como agentes culturais e membros ativos da família. Parecer haver também, embora nem sempre, como veremos, uma certa apreciação dos mais jovens em relação não só à sabedoria dos idosos, mas também à sua participação e inclusão social. Em várias ocasiões, Dias de Melo relata as folias e festejos locais em que todos, homens, mulheres, jovens e velhos convivem ("Isto não entrava no sonho dele", Melo, 1994, p. 90). A velhice, de modo nenhum, impede a participação do idoso na sua sociedade, nem nas atividades de diversão: "meu Tio Encrenca, anos a fio, Entrudo atrás Entrudo, fez e disse, mesmo depois de muito velho, bandos dos mais divertidos" ("Pena dela saudades de mim", MELO, 1994, p. 49).

Esta proximidade entre jovens e idosos justifica-se talvez pelo facto de que a realidade que nos retrata Dias de Melo - especialmente os anos antes da revolução democrática de 1974 - é marcada por um contexto socioeconómico muito específico de uma vivência insular de proximidade e de convívio íntimo entre todos. Como bem nos lembram Jon Hendricks e Cynthia Leedham (1989, p. 7), "uma ideologia de respeito aparece de forma mais pronunciada nas sociedades isoladas ou apartadas de influências externas”. Outro factor de importância que reforça a inclusão do idoso provém da pobreza sistémica dos Açores, que então compelia os idosos a trabalharem até uma idade muito avançada, muitos deles até ao fim da vida. Esta situação não é nada surpreendente, porque o direito à reforma era nessa época um privilégio negado aos mais pobres e humildes, que constituíam a maioria da população açoriana. Por este motivo, é comum encontrarmos com frequência na obra do escritor baleeiros, homens da terra e do mar (e mulheres também), que, com idades bastante avançadas, continuam a contribuir para a sociedade de forma produtiva. Ti Manuel Moita é talvez a personagem que melhor ilustra esta realidade:

Ti Manuel Moita, esse, mais baixo do que alto, era homem alentado, de ombros muito largos, costas abauladas, um tanto curvas, com aquela idade nem se assemelhava a um velho, mais se assemelhava a um toiro, metia num chinelo qualquer um que, na flor da mocidade, a seu lado se pusesse a cavar (MELo, 1996e, p. 37). 
O Ti Manuel Moita, para além de possuir uma vitalidade incrível, era um trabalhador exemplar, verdadeiro perito nos trabalhos da terra, um homem que "como melhor entendia fazia e mandava que fizéssemos, e assim é que estava certo" (p. 40). De facto, esta é uma das características positivas sobre a heterogeneidade do envelhecimento, pois "embora algumas habilidades cognitivas diminuam com a idade, outras, como por exemplo, o conhecimento profissional ou ocupacional, pode realmente aperfeiçoar-se” (DEATS; LENKER, 1999, p. 4).

Devido às dificuldades da vivência insular, encontramos também na obra de Dias de Melo uma velhice precoce, consequência de uma existência sofrida e brutal. No conto "Adormeceu a sonhar", a personagem principal relembra os pais há muito falecidos e como, mesmo quando estes eram jovens, já os via e sentia velhos: "o pai, pele encarquilhada, a roupa, um xadrez de remendos, de cotim as calças [...], a mãe, descalça, saia de fazenda grossa [...] na cabeça grisalha, o lenço de algodão amarrado para trás [...] andava com o pai pelos poucos bocadinhos de terra que possuíam [...] sem nada que chegasse para o ano inteiro" (Melo, 1996a, p. 182). Esta vivência, representativa da maior parte daqueles que Dias de Melo admira, o seu povo, reaparece ao longo das suas obras e é ilustrativa da vida de muitos. Vale a pena recordar também o envelhecimento prematuro de Maria em Pedras Negras, especialmente visível nas mãos. Após uma vida breve e padecida, as mãos de Maria passam de finas, mimosas, e delicadas a calejadas, gretadas, e encardidas (MELO, 2008, p. 154).

Para além da participação ativa dos idosos no mundo social e laboral na obra do autor, alguns deles vivem também a sensualidade e a sexualidade. Tal é o exemplo do homem de 65 anos (possivelmente o próprio escritor) do conto "Pétalas dispersas no ar", que todos os dias ao meio-dia toma banho de mar apesar de afirmar que "a gente da minha idade é gente de juízo na cabeça e vergonha na cara, [e] não vai, com tal carreto de anos, meter-se a andar na água salgada, agora!, isso é pra gente nova" (Melo, 1996c, p. 191). Mesmo assim, o mar é fonte de imenso prazer:

O deleite, o prazer do mergulho, eu entrando no mar, rompendo por baixo do mar, a grandes braçadas, enquanto debaixo do mar me aguento. $\mathrm{O}$ deleite, $\mathrm{o}$ prazer que me envolve, braços, pernas, seios de mulher que se me enlaçam, se me colam à pele, corpo de mulher que quer o meu corpo enterrado no corpo dela [...]. Fico-me a boiar, estirado, pernas unidas, braços abertos em cruz, repouso no ventre daquele corpo de mulher mais macio, aveludado, sensual, que os corpos de todas as mulheres do mundo. No alto, o céu imensamente azul 
e imensamente profundo. Ganhoas, garajaus, voando. Até que regresso a terra (MELO, 1996c, p. 192).

Noutra ocasião, é o Ti Manuel Moita que nos conta uma história já antiga da sua juventude. Havia muitos anos, o jovem Manuel tinha-se abrigado de chuvas torrenciais numa furna. Apesar da escuridão dentro dela, Manuel rapidamente percebeu que não estava só e que o outro ser que lá também se abrigava era mulher. Foi-se, como diz, chegando, chegando, até ter relações sexuais com a desconhecida. Quando a chuva diminui e se aclara o céu, Manuel repara que a companheira era uma "velha refunfelha, mais velha e refunfelha que a salvé rainha” (MELo, 1996e, p. 80). A rejeição da parceira surge apenas depois de Manuel dar conta da sua velhice e de ter admitido que "foi um consolo, a gaja era mestra naquilo" (MELo, 1996e, p. 80). Mas a velhice dela não tinha, afinal, influenciado negativamente nem o desempenho sexual nem a satisfação de Manuel.

Destacam-se, igualmente, o amor maduro e a sensibilidade como aspectos positivos da idade avançada. Em "Rosa Maria e Eduarda", o narrador relembra a amada afirmando: "amo-te, amas-me com um amor que, com a nossa idade, não podendo já ser feito com tanta carne, tanto sangue como o amor da juventude, é, todavia, feito de mais carinho, mais ternura, mais entrega, mais dádiva do espírito e do coração" (MELo, 2001d, p. 83-84). Numa carta de 2002 a Teresa Perdigão, em resposta às observações desta quando afirma que "ser solitário não é estarmos sós [...] e saber viver com nós próprios [...] saboreando com prazer as conversas que possamos ter com as pessoas," Dias de Melo amplia esta ideia ao afirmar que:

$$
\begin{aligned}
& \text { ou, acrescento eu, as que tivemos e, na minha idade, com os ausentes que } \\
& \text { amamos, com os entes queridos que já de nós para sempre se foram. E saber } \\
& \text { penetrar no mundo deles, próximo ou distante, procurar vê-los com os olhos do } \\
& \text { rosto e com os olhos da alma, com palavras inaudíveis falar-lhes, ouvi-los } \\
& \text { e compreendê-los (Melo, 2004a, p. 82-83). }
\end{aligned}
$$

Em alguns casos, a velhice proporciona a realização de projetos de vida. Assim é o caso de António Patrício que regressa à ilha depois de longa e infeliz estadia nos Estados Unidos. António passou a vida a sonhar com o mar, embora pouquíssimas vezes o tivesse visto após emigrar. Finalmente, aos 65 anos: 
reencontrou na vida o gosto que o regresso à ilha lhe dera [...] mandou fazer em Santo Amaro a lanchinha que pensava fazer, nela passou a ir, seu dono e mestre, ao mar, mesmo ao canal, é embarcação para isso [...]. Com a ilha, com estes mares da nossa ilha, o velho homem do mar renasceu para o mar (Melo, 2001a, p. 155).

Estes casos revelam a necessidade de uma reavaliação dos estereótipos tradicionais, visto que o envelhecimento pode também proporcionar crescimento, expansão e até emancipação (DEATs; LENKER, 1999, p. 3).

No entanto e apesar do idoso continuar e/ou querer viver dentro da sociedade a que pertence, Dias de Melo não ignora o desprezo, a rejeição e a vitimização social a que também o sujeita com frequência. Estes temas são abordados da perspetiva do próprio idoso, cujas histórias de vida nos impele a uma reflexão crítica, honesta e comovente. Tal é o caso, por exemplo, da "Velha professora" que, após passar a vida dedicada à formação intelectual dos seus alunos, encontra-se, triste, desolada e só, depois da reforma:

passava o tempo sem se aperceber de que o tempo passava, mas, obrigada (daquele modo grosseiro) a abandonar a escola, a apartar-se das suas alunas, tudo se tornara diferente, e ela vira-se como um barco destroçado, sem leme, sem bússola, sem governo, à deriva sobre as incertezas de um mar desconhecido (MELo, 1996f, p. 25).

Órfã de pais e com o único irmão já falecido, a velha professora vive à espera da visita das suas ex-alunas, mesmo ainda que "tanto lhe custara ir à loja, ir e vir a arrastar-se nas pernas trôpegas, pelos caminhos maus [...] mas fora - e ali estavam, prontinhas, as amêndoas à espera, faltava só que elas chegassem, as antigas alunas" (MELo, 1996f, p. 27). Infelizmente, ninguém vem, a noite chega e "a alma da velha professora, na cadeira do canto, só, completamente só, sepultada na escuridão... a escuridão da noite que ela receava tanto... da noite cheia de pavores daquele Inverno sem Primavera" (Melo, 1996f, p. 28). O mesmo acontece com o idoso de "Adormeceu a sonhar". Só, noite após noite, ele recorda o passado já que o presente é de total solidão: "Só. Na cozinha negra. Na casa velha. Na pequenina freguesia" (Melo, 1996a, p. 188). Mesmo o risonho narrador de "Pétalas dispersas no ar" admite que, apesar de haver outros banhistas, se sente só: "desertou a infância e a juventude que aí vinham [...]. E mesmo quando aí andam a infância e a juventude, eu - só: o fosso que se cava entre gerações" (MElo, 1996a, p. 191). Estes e outros exemplos, obrigam-nos a encarar não só uma realidade que nos toca a todos, mas também a vermos a humanidade do idoso, ser que, tal como qualquer um de nós, se 
sente, se entristece e se angustia perante o desprezo coletivo e a inevitável solidão.

Dias de Melo aborda também a problemática das muitas limitações físicas que podem apoquentar o idoso, talvez porque nas últimas décadas se tenham tornado mais visíveis as marcas irreversíveis da velhice de um homem atento e consciente das suas muitas milhas contadas. As recordações do passado, dos muitos que já faleceram, e a crueldade do tempo que passa e debilita o corpo, são referências constantes na obra de Dias de Melo: "É como se, à medida que vamos caminhando, que nos aproximamos do nosso próprio fim, não deixemos atrás de nós senão um cemitério" (MElo, 1996g, p. 122); "crueldade das crueldades os velhos terem de se arredar e morrer para darem lugar aos novos" (Melo, 1996 d, p 134); “ um dia lhe tremeram as mãos, um dia lhe vacilaram as pernas, um dia lhe minguou a vista, um dia lhe embranqueceram os cabelos, um dia lhe engelhou a pele, um dia lhe fraquejou a coragem, a força ... um dia ... um dia ... pobre menino velho da pobre Mãe já morta” (Melo, 1996b, p 180).

A chegada, muitas vezes súbita, da velhice, é abordada também na obra do escritor. No conto "Capitão do mar e da saudade," Raimundo pondera sobre a sua vida ativa, aventurosa, dedicada ao mar. Até que um dia, sem dar por isso, envelhece. O narrador desabafa:

Nós, enquanto novos, pensamos que a velhice é coisa que não nos diz respeito, que só acontece aos outros. Mesmo quando vão os anos passando e chegamos aos cinquenta ... sessenta ... e já estamos a entrar nela. A velhice e a morte ... E eu, sem dar por isso, sentindo-me em pleno vigor, sem de tanto me aperceber entrara mesmo na velhice (Melo, 2001a, p. 107).

Em Poeira do caminho, Dias de Melo regista "o recordar da vida que viv[eu] e daquela que ir[á] vivendo, consciente de que "com a [sua] idade, não será por muito tempo" (MeLo, 2004b, p. 9). Neste livro percorremos com o autor alguns dos mais belos lugares da sua ilha, partilhamos com ele momentos alegres da sua juventude, frustrações do seu dia-a-dia, saudades de muitos que já se foram. No entanto, um dos momentos mais marcantes que o autor nos descreve é sobre a sua própria velhice. Na crónica sobre o Mestre José Faidoca e a morte de Ti Machadinho, Dias de Melo manifesta a sua alegria quando, ao regressar ao Pico, ser sempre tratado por tu; o autor confessa que este tratamento informal lhe dava imenso prazer porque significava que, embora 
não vivesse permanentemente no Pico, as pessoas não se esqueciam dele e que aliás, o fazia sentir-se jovem, dado que o tratamento de "tu" é geralmente associado aos jovens. A revelação da sua velhice chega-lhe repentina e tragicamente:

embora não me esquecendo de que os anos iam passando e deixando em mim, como em todos, as marcas da sua passagem, senti-me triste, muito triste, quando, numas férias, ao chegar aqui, me começarem a tratar por senhor ou por ti... já os cabelos brancos me abundavam por demais na cabeça e trazia por primeira vez, uns óculos escanchados na cana do nariz (Melo, 2004b, p. 25).

A apreensão abrupta da velhice provoca o que Amelia DeFalco denomina the uncanny, um conceito influenciado por Freud que incita a uma desestabilização, neste caso a uma confrontação temporal intensificada pela diferença entre o passado e o presente (DeFAlco, 2010, p. 6-7). A novidade do corpo, agora velho, é transtornadora, ao mesmo tempo estranha e familiar, torna-se muitas vezes um recurso literário e cinematográfico que conduz a profundas reflexões identitárias (DeFAlco, 2010, p. 10). Enfim, a chegada da velhice que se revela nos cabelos brancos, nos óculos ou até, como vemos no caso de Raimundo, em ter de abandonar o comando do Calipso, o seu barco, é, apesar de repentina, inevitável. Como bem nota o escritor, em Milhas Contadas, "os velhos, dia a dia mais velhos ... a juventude perdida ... longe ... e a morte a aproximar-se, a aproximar-se ... tanto ... tanto ..." (Melo, 2002, p. 78).

O desprezo colectivo e a marginalização do idoso são tragédias que Dias de Melo consegue captar muito bem e, ao fazê-lo assim tão eficazmente, consegue sensibilizar o leitor para esse mal social do nosso mundo contemporâneo. Muitos são aqueles que aparecem na obra do escritor na mais completa solidão e abandono. Na coletânea de contos natalícios Uma estrela nas mãos do homem, Dias de Melo refere-se à sua idade dizendo que: "o fim aproxima-se. Espero-o e aceito-o serenamente" (MELO, 1986, p. 14). O escritor elogia a amizade e a solidariedade colocando o livro "nas vossas mãos de Juventude e Esperança" (Melo, 1986, p. 15). O que seguem são, na sua maioria, contos curtos de variada temática, mas em muitos predominam a velhice e a solidão. Consciente da sua velhice, não seria por acaso que Dias de Melo decidiu incluir tais temas numa coleção de contos de cariz natalício. Possivelmente, seria uma tentativa de nos sensibilizar durante uma época em que se clama pela humanidade e a bondade. De facto, a maioria dos contos aborda os ditos temas - "Os velhos," "Velha tia velha professora," "Já não é nossa a nossa casa," "Noite caindo," entre outros - 
sensibilizam-nos porque nos apresentam seres humanos completamente sós durante a época festiva. Cabe realçar a pobreza que une este grupo etário e que ainda mais os desola: são, na sua maioria, "velhos, [na] berma do caminho de pó e lama, [na] noite de Natal" ("Neste mundo sem ninguém"). Para cima de uma década mais tarde, o escritor recorda-nos esta realidade no conto intitulado "Eles", sobre um casal de idosos cujos nomes nunca chegamos a saber. Sabemos apenas que se encontram velhos, sós e abandonados. Ele e ela envelhecem de dia para dia, facto não só evidente nos cabelos alvos de neve. Sentem cada vez mais dificuldades, no andar, no ver, no ouvir, e nas "forças tão minguadas dos corpos ressequidos e encarquilhados, nos braços quase pele e osso, nas mãos descarnadas, inseguras, trémulas... mal lhes chegavam para levantar do chão, nem que fosse uma pena de galinha" (Melo, 2001c, p. 18). Ele e ela, apesar das muitas limitações físicas e económicas, vivem sós, recebendo poucas ou nenhumas notícias dos cinco filhos, há muito emigrados. Um dia, porém, recebem notícia de que em breve terão uma visita dos filhos; ele e ela, conscientes de que a humilde casa não poderá servir os filhos nem os netos, já acostumados aos confortos da América, gastam as suas poucas e últimas poupanças e acumulam novas dívidas no conserto da casa para melhor poderem receber as visitas. Um dia, já passado mais de um ano da carta inicial, chegam filhos, genros, noras, netos. Ele e ela comovidos, mostram aos filhos os arranjos da casa e indagam sobre a estadia. Inesperadamente, o filho mais velho revela que estão hospedados no hotel da vila e que lá deixaram jantar apalavrado. Para além disso, partiam no dia seguinte, no avião das 1oh. Depois de tanto esforço, ele e ela não conseguem resistir ao desprezo da família. Ela morre pouco tempo depois e ele,

mais infeliz ficou, desgraçada e miseravelmente só, com a casa perdida a dormir por onde calhava, até que, por esmola, foi acabar os seus dias na Casa de velhos da vila da Fronteira da Ilha. Ainda assim teve sorte: na Casa de Velhos da fronteira da Ilha, aos velhos tratavam bem (Melo, 2001c, p. 40).

A ausência de nomes próprios revela-se trágica na medida em que esta situação poderá ocorrer a qualquer um de nós porque, infelizmente, os novos, como bem nos previne o escritor nas suas Milhas contadas, nem sempre ouvem com interesse os mais velhos, "nem acreditam que, se não tombarem também um 
dia serão velhos e nem se lembram, nem sabem, que são as vidas do Passado que constroem a vida do Presente e alicerçam a do Futuro" (Melo, 2002, p. 119).

Dias de Melo apresenta-nos narrativas múltiplas sobre a representação literária do idoso. A velhice é uma etapa complexa que não pode, nem deve, ser interpretada apenas como derradeira; ela contribui para a realização pessoal e pode ter um cariz libertador. A solidão e o desprezo em relação ao idoso são temas apresentados por ele de maneira crítica que não só nos despertam e nos emocionam, como também nos obrigam a nos identificarmos com os idosos e a vê-los como seres humanos, como nós.

Sara Deats e Lagretta Lenker (1999, p. 1) afirmam que a arte e a literatura não só refletem convenções sociais, mas também têm o poder de as produzir e desconstruir. Estas autoras, seguindo já estudos recentes sobre o envelhecimento, argumentam que o campo das Humanidades não deve ser limitado ao puramente académico e que se torna indispensável ao diálogo sobre esta etapa, o tal ingrediente que falta à aproximação científica e profissional dessas disciplinas. A literatura, por exemplo, "por oferecer perspectivas múltiplas e porque evoca a simpatia, tende a estimular a tolerância, a abertura das mentalidades e a compaixão, valores vitais para o estudo do envelhecimento" (Deats; Lenker, 1999, p. 8). Eis Dias de Melo, escritor ilhéu de temática baleeira, a ultrapassar os limites da ilha e a conquistar-nos com a sua humanidade intergeracional.

\section{Referências}

Archambault, Paul J. From centrality to expendability: the aged in French literature. Dorotka, Prisca von; Soper, Patricia Spencer (Eds.). Perceptions of aging in literature: a cross-cultural study. New York: Greenwood Press, 1989.

Beauvoir, Simone de. The coming of age. Tradução de Patrick O’Brian. New York: Putnam, 1972.

DeAts, Sara Munson; Lenker, Lagretta Tallent (Ed.). Aging and identity: a humanities perspective. Westport, Conn.: Praeger, 1999.

DeFalco, Amelia. Uncanny subjects: aging in contemporary narrative. Columbus: Ohio State U. Press, 2010.

FALLIS, Richard C. "Grow Old along with me": images of older people in British and American literature. In: Dorotka, Prisca von; Soper, Patricia Spencer (Eds.). Perceptions of aging in literature: a cross-cultural study. New York: Greenwood Press, 1989.

Hendricks, Jon; LeEdHAM, Cynthia A. Making sense: interpreting historical and cross-cultural literature on aging. In: Dorotka, Prisca von; Soper, Patricia Spencer (Eds.). Perceptions of aging in literature: a cross-cultural study. New York: Greenwood Press, 1989. 
Melo, José Dias de. Toadas do mar e da terra. Ponta Delgada: Oficina de Artes Gráficas, 1954.

Melo, José Dias de. Uma estrela nas mãos dos homens. Ponta Delgada: Brumarte, 1986.

Melo, José Dias de. Isto não entrava no sonho dele. In: Melo, José Dias de. Pena dela saudades de mim. Lisboa: Salamandra, 1994.

Melo, José Dias de. Adormeceu a sonhar. In: Melo, José Dias de. Inverno sem primavera. Lisboa: Salamandra, $1996 a$.

Melo, José Dias de. Círculo. In: Melo, José Dias de. Inverno sem primavera. Lisboa: Salamandra, $1996 b$.

Melo, José Dias de. Pétalas dispersas no ar. In: Melo, José Dias de. Inverno sem primavera. Lisboa: Salamandra, $1996 c$.

Melo, José Dias de. Renasceu para o mar. In: Melo, José Dias de. Inverno sem primavera. Lisboa: Salamandra, 1996d.

Melo, José Dias de. Ti Manuel Moita. In: Melo, José Dias de. Inverno sem primavera. Lisboa: Salamandra, 1996e.

Melo, José Dias de. Velha professora. In: MELO, José Dias de. Inverno sem primavera. Lisboa: Salamandra, $1996 f$.

Melo, José Dias de. Velho trancador de baleias. In: Melo, José Dias de. Inverno sem primavera. Lisboa: Salamandra, 1996 g.

Melo, José Dias de. Capitão do mar e da saudade. In: Melo, José Dias de. À boquinha da noite. Lisboa: Salamandra, 2001a.

Melo, José Dias de. Carta com destino. In: Melo, José Dias de. À boquinha da noite. Lisboa: Salamandra, $2001 b$.

Melo, José Dias de. Eles. In: Melo, José Dias de. À boquinha da noite. Lisboa: Salamandra, $2001 c$.

Melo, José Dias de. Rosa Maria e Eduarda. In: Melo, José Dias de. À boquinha da noite. Lisboa: Salamandra, 2001d.

Melo, José Dias de. Milhas contadas. Lisboa: Salamandra, 2002.

Melo, José Dias de. Carta para a Dra. Teresa Perdigão. In: Melo, José Dias de. Poeira do caminho: reminiscências do passado, vivências do presente. Porto: Campo das Letras, $2004 a$.

Melo, José Dias de. Poeira do caminho: reminiscências do passado, vivências do presente. Porto: Campo das Letras, $2004 b$.

Melo, José Dias de. Pedras negras. 4. ed. Ponta Delgada: Veraçor, 2008.

SuÁREz, José I. Characterization of the Elderly in Vicentine drama. South Atlantic Review, v. 62, n. 1, p. 33-42, 1997.

Thane, Pat (Ed.). A history of old age. Los Angeles: J. Paul Getty Museum, 2005.

Woodward, Kathleen. Aging and its discontents: Freud and other fictions. Bloomington: Indiana University Press, 1991.

Recebido em 19 de fevereiro de 2017.

Aprovado em 8 de março de 2017. 


\section{Resumo/Abstract/Resumen}

\section{Representações da velhice e do envelhecimento na obra de Dias de Melo}

Maria João Dodman

O presente trabalho explora a temática do envelhecimento e da velhice na obra do escritor açoriano José Dias de Melo. Partindo da atual perceção negativa e da exclusão do idoso, especialmente nas produções literárias e artísticas, o artigo apresenta vários aspetos positivos em que o escritor açoriano não só revaloriza o idoso como também reivindica a sua humanidade, valor social, económico e cultural. Configuram-se assim novas e positivas formas de ser e viver a velhice. Por outro lado, e sem esquecer o desprezo social que atualmente se observa quanto ao idoso, Dias de Melo induz-nos a uma reflexão comovente sobre o tema em um processo de autoidentificação, bondade e respeito.

Palavras-chave: José Dias de Melo, velhice, envelhecimento, Açores.

\section{Representations of old age and aging in the work of Dias de Melo}

Maria João Dodman

This paper explores the theme of aging and old age in the works of Azorean writer José Dias de Melo. Departing from the current negative perception and the exclusion of the elderly, especially in literary and artistic productions, the article presents several positive aspects where the Azorean writer not only values the elder, but also reclaims his/hers humanity, social, economic and cultural value. New positive ways of being and living with old age are configured. On the other hand, and without forgetting the social scorn present in today's society, Dias de Melo leads us into a moving reflection on the theme in a process of self-identification, kindness and respect.

Keywords: José Dias de Melo, old age, aging, Azores.

\section{Representaciones de la vejez y del envejecimiento en la obra de Dias de Melo}

Maria João Dodman

Este trabajo explora la temática del envejecimiento y de la vejez en la obra del escritor de las Azores José Dias de Melo. Tomando como punto de partida la actual percepción negativa y de exclusión hacia el viejo, sobre todo en las producciones literarias y artísticas, el artículo presenta varios aspectos positivos en los que el escritor azoriano no solo revaloriza al anciano, sino que también reivindica su humanidad y su valor social, económico y cultural. De este modo se configuran nuevas y positivas formas de ser y de vivir la vejez. Por otra parte, y sin olvidar el desprecio social que se hace patente en la actualidad en cuanto al viejo, Dias de Melo nos lleva a una reflexión conmovedora sobre el tema en un proceso de autoidentificación, amabilidad y respeto.

Palabras clave: José Dias de Melo, vejez, envejecimiento, Azores. 